\title{
Pharmacotherapy of Systemic Vasculitis Combined with Cryoglobulinemic Syndrome Using Pharmacoeconomic Approaches
}

\author{
Ihor Hayduchok ${ }^{1}$ \\ ${ }^{1}$ Lviv Medical Institute LLC, Lviv, Ukraine \\ Correspondence: Ihor Hayduchok, Lviv Medical Institute LLC, Lviv, Ukraine. Tel: 380-91-999-9961.
}

Received: April 20, 2021 Accepted: May 20, 2021 Online Published: June 3, 2021

doi:10.5539/gjhs.v13n7p78 URL: https://doi.org/10.5539/gjhs.v13n7p78

\begin{abstract}
Background: It was substantiated the relevance and necessity of the chosen research topic as a result of a review of the scientific literature on the epidemiology and pharmacotherapy of patients with systemic vasculitis associated with cryoglobulinemic syndrome.
\end{abstract}

Objective: In this study were selected drugs that have the diagnostic ATC-code J05 Antiviral agents for systemic use; J05A Antivirals of direct action; J05AB01 antiviral agents for systemic use according to INN Aciclovir.

Methods: This study is based on pharmacoeconomic, organizational and legal, forensic and pharmaceutical approaches to pharmacotherapy with using literature review. Experimental data were processed on the basis of the Department of Internal Medicine of the Lviv Medical Institute and the Department of Medical and Pharmaceutical Law, General and Clinical Pharmacy of the Kharkiv Medical Academy of Postgraduate Education.

Results: Clinical and pharmacological analysis of basic therapy of systemic vasculitis was performed. Pharmacoeconomic studies have been conducted. According to the results of $\mathrm{ABC}$ analysis, drugs according to INN Aciclovir ATC-code J05AB01 for pharmacotherapy of patients with systemic vasculitis combined with cryoglobulinemic syndrome were distributed in descending order of value. According to the results of VEN-analysis, it is estimated that category $\mathrm{V}$ drugs accounted for the largest number of prescriptions and the cost of therapy $(100 \%)$.

Conclusion: This study provide an opportunity to make administrative and managerial decisions in determining the pharmacotherapy of patients with systemic vasculitis combined with cryoglobulinemic syndrome to improve the use of drugs in hospitals.

Keywords: pharmaceuticals, systemic vasculitis, cryoglobulinemic syndrome, pharmacoeconomic, ABC-VEN analysis.

\section{Introduction}

Systemic vasculitis is a large group of pathological conditions in which the vessels of the body are affected. There are signs of inflammation of the vascular wall, blood clots, impaired blood flow, as well as secondary changes in organs and systems, the clinical manifestations of which depend on the location and caliber of the affected vessels (Vasculitis: Five Drugs to Control This Mysterious Blood Vessel Illness, 2017).

Systemic vasculitis is one of the most severe forms of chronic pathology, which is complicated by pulmonary hemorrhage, myocardial infarction, renal failure, neurological disorders, gangrene of the extremities (Kuzmina, 2015).

The annual incidence of primary vasculitis in children and adolescents under the age of 17 is from 12 to 53 cases per 100 thousand. Primary vasculitis is diagnosed among $2-10 \%$ of patients observed in pediatric rheumatology departments (Marushko, 2020).

The etiology of systemic vasculitis is unknown. The cause of inflammatory vascular damage can be an infection or chemical factors. Hypersensitivity to drugs (antibiotics, antivirals, etc.) plays an important role in the development of small vasculitis. The pathogenesis of systemic vasculitis is based on defects of innate and adaptive immunity with impaired regulation of B cells, pathogenic production of antineutrophil cytoplasmic antibodies, activation of neutrophils and imbalance between helper and effector $T$ cells. Neutrophils are the main cells that initiate damage to endothelial cells and tissues, which lead to inflammation of the walls of blood vessels. As a result of the action 
of immune and non-immune mechanisms on the vascular wall, cellular immunity is activated; synthesis of proinflammatory cytokines, autoantibodies and adhesion molecules is accompanied by dysfunction and endothelial damage, development of inflammation. Inflammatory damage to the walls of blood vessels causes the formation of blood clots, ischemic damage to the tissues in the blood supply of which these vessels are involved (Marushko, 2020).

Depending on the reactions underlying vascular damage, cellular mechanisms are distinguished when granulomas are formed (for example, giant cell arteritis) and humoral mechanisms are the formation of immune complexes through immune, including autoimmune reactions, which triggers a cascade of inflammatory reactions in vessels (Vasculitis: Five Drugs to Control This Mysterious Blood Vessel Illness, 2017).

Patients in remission receive maintenance treatment for at least 12 months. Relapses are common, with $50 \%$ of patients having relapses within five years (Vincent et al., 2015).

The US vasculitis pharmaceutical market is expected to grow at a rate of $3.8 \%$ per year for the decade from 2014 to 2024, reaching sales of $\$ 316$ million (Fellner, 2016).

With the spread of the coronavirus pandemic (Shapovalova et al., 2020), the role of pharmacotherapy of systemic vasculitis on the background of cryoglobulinemic syndrome among patients with dual health disorders (Hayduchok et al., 2020) and among patients with systemic diseases (Hayduchok et al., 2020) becomes very relevant.

Despite numerous publications on COVID-19, at present, conceptual thinking of the problem is only at a nascence stage. Treatment of patients with ANCA-associated systemic vasculitis (AAV) during the COVID-19 pandemic is one of the most relevant issues. Further analysis of COVID-19 among patients with AAV is important (Beketova, 2019).

Previously, the experience of the USA concerning and organization of healthcare system for the pharmaceutical provision for privileged categories of citizens was written (Shapovalov (Jr.) et al., 2019); forensic and pharmaceutical analysis of addictive morbidity because of the use of psychoactive substances in Ukraine (Shapovalov (Jr.) et al., 2020); experience of Great Britain in the organization of healthcare system for pharmaceutical provision with medicines for privileged categories of citizens (Shapovalov (Jr.) et al., 2019).

Today it is important to use modern, effective and safe drugs for pharmacotherapy of systemic vasculitis combined with cryoglobulinemic syndrome. Pharmacoeconomic methods of analysis, in particular ABC/VEN analysis, are used to select effective, safe and affordable drugs.

The purpose of this research was to analyze the pharmacotherapy of systemic vasculitis combined with cryoglobulinemic syndrome using pharmacoeconomic approaches.

\section{Methods}

\subsection{Study Design and Setting}

This study was a quantitative study design which was conducted from the $19^{\text {th }}$ of September 2020 to the $19^{\text {th }}$ of December 2020. It was conducted in selected public healthcare facilities in Ukraine. The facility-based quantitative descriptive cross-sectional study was conducted using a standard data collection tool. Experimental data were processed on the basis of the Department of Internal Medicine of the Lviv Medical Institute and the Department of Medical and Pharmaceutical Law, General and Clinical Pharmacy of the Kharkiv Medical Academy of Postgraduate Education.

Study Design is based on pharmacoeconomic, organizational and legal (Shapovalov (Jr.), Zbrozhek et al., 2018), forensic and pharmaceutical (Shapovalova et al., 2021) approaches to pharmacotherapy with using literature review.

The research of the article is a fragment of research works of Lviv Medical Institute LLC on the topic "Improvement of the drug circulation system during pharmacotherapy on the basis of evidentiary and judicial pharmacy, organization, technology, biopharmacy and pharmaceutical law" (state registration number 0120U105348, terms 2021-2026), Kharkiv Medical Academy of Postgraduate Education on "Improving the organizational and legal procedure for providing patients with drugs from the standpoint of forensic pharmacy, organization and management of pharmacy" (state registration number 0116U003137, terms 2016-2020) and "Pharmaceutical and medical law: integrated approaches to the system of drug circulation from the standpoint of forensic pharmacy and organization of pharmaceutical business" (state registration number D/21U000031, terms 2021-2026) (Shapovalov (Jr.) et al., 2017). 


\subsection{Study Population and Sample}

The study population included accounting the hospitals 'comprehensive medicine list development by the pharmaceuticals and therapeutic committee for patients with systemic vasculitis combined with cryoglobulinemic syndrome. During the study of the medical records of patients, prescribed drugs for marketing and pharmacoeconomic analysis were allocated.

The study processed pharmaceuticals from 380 medicine cards of patients with systemic autoimmune diseases who attended public healthcare clinics in Lviv and Kharkiv regions of Ukraine.

The study population included selection of clinical and pharmacological groups of drugs for basic pharmacotherapy of systemic vasculitis according to clinical protocols. Separately performed the selection of drugs for pharmacotherapy of cryoglobulinemic syndrome.

All pharmaceuticals were purchased using a revolving drug fund in public health clinics between 2018 and 2019 .

\subsection{Sampling and Sample Size}

The study subjects were all pharmaceuticals for pharmacotherapy of patients with systemic vasculitis combined with cryoglobulinemic syndrome. The USAID delivery project logistics indicator assessment tool was employment to determine the sample size of health facilities. It recommends a minimum of $15 \%$ of the total health facilities inclusion (Snow, 2005).

According to the clinical and pharmacological group for pharmacotherapy of patients with systemic vasculitis combined with cryoglobulinemic syndrome were selected drugs that have the diagnostic code ATC - Classification (ATC): J05 Antiviral agents for systemic use; J05A Antivirals of direct action; J05AB01 antiviral agents for systemic use according to INN Aciclovir (ATC-classification, 2020).

\subsection{Data Collection Tools}

$\mathrm{ABC}$ analysis was applied as a method for classifying pharmaceuticals based on cost incurred. A structured data collection from Management Science for Health was used to collect the necessary data for ABC analysis (Management Science for Health, 2012).

VEN analysis was applied as a method of prioritizing pharmaceuticals based on public health importance as vital, essential and non-essential (Mamarde, 2016).

A structured data collection from Management Science for Health was used to collect the necessary data for VEN analysis (Management Science for Health, 2012).

VEN data were generated from hospitals 'comprehensive medication cards development by the pharmaceuticals and therapeutic committee.

At the preparatory stage of the study, a superficial analysis of the study materials was performed in order to eliminate improperly completed questionnaires and calculate the minimum number of them to obtain representative data of the study results according to the formula:

$$
n=\frac{N}{1+0.015 \cdot N}
$$

where $\mathrm{n}$ - is the number of questionnaires;

$\mathrm{N}-$ is the total number of medicine cards.

The questionnaire in this study was developed to collect data from medical cards by taking questions from previous similar studies and using literature review (Shapovalov (Jr.) et al., 2017).

The questionnaire consisted of 15 questions which were divided into 3 sections. Section one had four background questions, Section Two had five knowledge questions, Section Three had six practice-related questions.

For the knowledge related questions, each "vital" answer was coded as " 5 ", "essential" as " 3 " and a "non-essential" as " 0 ".

Pharmaceuticals were listed using Microsoft Excel.

\subsection{Study Procedure}

For ABC analysis

To assess the cost of pharmacotherapy for patients with systemic vasculitis on the background of cryoglobulinemic syndrome $\mathrm{ABC}$ analysis was performed as a tool to study the cost of purchasing drugs. $\mathrm{ABC}$ analysis involves the 
distribution of drugs from the most to the least expensive depending on their share among the indicators of the general purpose of pharmaceuticals.

\section{For VEN analysis}

To assess the effectiveness of drug use, a VEN analysis was performed to classify drugs into categories V (vital), E (essential) and $\mathrm{N}$ (non-essential), taking into account regulatory documents: medical care standards, clinical protocols, State Form of Medicines (Order of the Ministry of Health of Ukraine, 2020), National List of Essential Medicines (National list of basic medicines, 2009) and principles of evidence-based medicine (evidence of efficacy, quality, safety, economy, affordability). The following approach was used in this analysis: the division of drugs into categories V - "Vital"; E - "Essential" and N - "Non-essential" (Shapovalov (Jr.), Gudzenko et al., 2018).

\subsection{Data Management and Analysis}

The quantity of all drugs for $\mathrm{ABC}$ analysis was entered, the percentage of total value was calculated in descending order by value starting at the top with higher value. Then the cumulative percentage by value, and items were computed, and cutoff points for pharmaceuticals A, B, C were determined based on the Pareto principle. Finally, the ABC-VEN matrix was developed.

Analysis of the quantitative data was done by using Microsoft Excel and Statistical Package for Social Sciences version 20.

\section{Results}

\subsection{General Characteristics}

In the International Classification of Diseases of the $10^{\text {th }}$ edition systemic vasculitis refers to diseases of the musculoskeletal system, where twelve blocks are isolated. For example, M30 - nodular polyarthritis and related conditions; M31 - other necrotizing vasculopathies; M35 - other systemic connective tissue lesions. Small vessel vasculitis includes immunoglobulin A vasculitis, cryoglobulinemia vasculitis, and hypersensitivity vasculitis.

Henoch-Schönlein purpura (IgA vasculitis) has the code of the International Classification of Diseases 10 edition D69 "Purpura and other hemorrhagic conditions" class "Diseases of the blood, blood-forming organs and certain disorders involving immune mechanisms". The code of the International Classification for Primary Care-2 is B83 (Hayduchok et al., N.64-2021).

Henoch-Schönlein purpura is a hemorrhagic vasculitis with IgA-immune deposits that affects small vessels (capillaries, venules, arterioles).

In international treatment protocols, Henoch-Schönlein purpura is called IgA-associated vasculitis (Fellner, 2016).

Basic pharmacotherapy of systemic vasculitis includes drugs included in clinical international and national protocols: Heparin, Acetylsalicylic acid, Prednisolone, Ciclosporin, Paracetamol, Hydroxychloroquine, Ergocalciferol, Azithromycin, Pancreatin.

In international clinical protocols (International Guideline 00653, 2016; International Guideline 00449, 2017), pharmacotherapy of vasculitis includes glucocorticoids as monotherapy, glucocorticoids in combination with cytotoxic agents. Corticosteroids help reduce inflammation in blood vessels, and cytotoxic drugs kill immune-causing cells in the immune system (Fellner, 2016).

\subsection{Clinical and pharmacological analysis}

Clinical and pharmacological analysis of drugs for basic therapy of patients with systemic vasculitis is given in Table 1. 
Table 1. Clinical and pharmacological distribution of drugs for pharmacotherapy of patients with systemic vasculitis

\begin{tabular}{|c|c|c|}
\hline No. & Clinical and pharmacological group & ATC code \\
\hline 1. & $\begin{array}{l}\text { Direct anticoagulants } \\
\text { Heparin }\end{array}$ & B01AB01 \\
\hline 2. & $\begin{array}{l}\text { Glucocorticosteroids } \\
\text { Prednisolone }\end{array}$ & H02АB06 \\
\hline 3. & $\begin{array}{l}\text { Antibiotics } \\
\text { Azithromycin }\end{array}$ & J01FA10 \\
\hline 4. & $\begin{array}{l}\text { Immunosuppressive drugs } \\
\text { Ciclosporin }\end{array}$ & L04AD01 \\
\hline 5. & $\begin{array}{l}\text { Antiplatelet agents } \\
\text { Acetylsalicylic acid }\end{array}$ & N02BA01 \\
\hline 6. & $\begin{array}{l}\text { Nonsteroidal anti-inflammatory drugs } \\
\text { Paracetamol }\end{array}$ & N02BE01 \\
\hline 7. & $\begin{array}{l}\text { Systemic enzyme therapy drugs } \\
\text { Pancreatin }\end{array}$ & A09AA02 \\
\hline 8. & $\begin{array}{l}\text { Vitamins } \\
\text { Ergocalciferol }\end{array}$ & $\mathrm{A} 11 \mathrm{CC} 01$ \\
\hline 9. & $\begin{array}{l}\text { Aminoquinolone drugs } \\
\text { Hydroxychloroquine }\end{array}$ & P01BA02 \\
\hline
\end{tabular}

\subsection{Particularities of Cryoglobulinemic Syndrome}

Cryoglobulinemic syndrome is an immune-dependent process caused by the presence in the serum of pathological proteins - cryoglobulins, which are reversely precipitated at temperatures below $37^{\circ} \mathrm{C}$ in vessels of small and medium caliber, which often leads to the development of systemic vasculitis.

Internationally accepted international standards for the treatment and prevention of patients with various forms of cryoglobulinemic syndrome have not yet been developed, and the proposed current recommendations are based on the results of open research or retrospective analysis.

With the personal participation of the author, the scheme of pharmacotherapy with the use of antiviral therapy on the background of basic and concomitant therapy for the treatment of underlying and comorbidities was tested.

Pharmacotherapy of systemic vasculitis associated with cryoglobulinemic syndrome included the use of antiviral drugs according to INN Aciclovir ATC-code J05AB01.

3.4 Marketing research

Marketing research of medicines according to INN Aciclovir ATC-code J05AB01 (Table 2) was carried out. 
Table 2. Marketing analysis of drugs according to INN Aciclovir ATC-code J05AB01 for pharmacotherapy of patients with systemic vasculitis associated with cryoglobulinemic syndrome

\begin{tabular}{|c|c|c|c|}
\hline No. & $\begin{array}{l}\text { Trade name / } \\
\text { Manufacturer }\end{array}$ & $\begin{array}{l}\text { Dosage form, } \\
\text { strength, } \\
\text { amount per unit }\end{array}$ & $\begin{array}{l}\text { Number, validity period from/until } \\
\text { according to the registration certificate } \\
\text { of the medicines }\end{array}$ \\
\hline 1. & $\begin{array}{l}\text { Atsik, } \\
\text { Salutas Pharma GmbH, } \\
\text { Germany }\end{array}$ & $\begin{array}{l}\text { tablets, } \\
200 \mathrm{mg}, \\
\text { N. } 25\end{array}$ & $\begin{array}{l}\text { UA/14584/01/01 } \\
\text { Unlimited from } 04.08 .2020\end{array}$ \\
\hline 2. & $\begin{array}{l}\text { Viroleks, } \\
\text { KRKA, dd, Novo mesto, } \\
\text { Slovenia }\end{array}$ & $\begin{array}{l}\text { tablets, } \\
200 \mathrm{mg}, \\
\text { N. } 20\end{array}$ & $\begin{array}{l}\text { UA/2526/01/01 } \\
\text { Unlimited from 16.08.2019 }\end{array}$ \\
\hline 3. & $\begin{array}{l}\text { Geviran, } \\
\text { Pharmaceutical plant "POLPHARMA" SA, } \\
\text { Poland }\end{array}$ & $\begin{array}{l}\text { tablets, } \\
200 \mathrm{mg}, \\
\text { N. } 30\end{array}$ & $\begin{array}{l}\text { UA/7565/01/01 } \\
\text { Unlimited from 29.11.2017 }\end{array}$ \\
\hline 4. & $\begin{array}{l}\text { Aciclovir } 200 \text { STADA, } \\
\text { HERDS Arnzeimittel AG, } \\
\text { Germany }\end{array}$ & $\begin{array}{l}\text { tablets, } \\
200 \mathrm{mg}, \\
\text { N. } 25 \text {, N. } 100\end{array}$ & $\begin{array}{l}\mathrm{UA} / 3840 / 01 / 01 \\
\text { Unlimited from 26.01.2021 }\end{array}$ \\
\hline 5. & $\begin{array}{l}\text { Zoviraks, } \\
\text { Glaxo Wellcome SA, } \\
\text { Spain }\end{array}$ & $\begin{array}{l}\text { tablets, } \\
200 \mathrm{mg}, \\
\text { N. } 25\end{array}$ & $\begin{array}{l}\text { UA/8281/03/01 } \\
\text { Unlimited from 21.06.2018 }\end{array}$ \\
\hline 6. & $\begin{array}{l}\text { Herpevir, } \\
\text { PJSC “Kyivmedpreparat”, } \\
\text { Ukraine }\end{array}$ & $\begin{array}{l}\text { tablets, } \\
200 \mathrm{mg}, \\
\text { N. } 20\end{array}$ & $\begin{array}{l}\mathrm{UA} / 2466 / 03 / 01 \\
\text { Unlimited from 21.09.2016 }\end{array}$ \\
\hline 7. & $\begin{array}{l}\text { Aciclovir-Darnitsa, } \\
\text { PJSC “Pharmaceutical firm” Darnitsa, } \\
\text { Ukraine }\end{array}$ & $\begin{array}{l}\text { tablets, } \\
200 \mathrm{mg} \text {, } \\
\text { N. } 20\end{array}$ & $\begin{array}{l}\text { UA/0991/01/01 } \\
\text { Unlimited from 21.03.2019 }\end{array}$ \\
\hline 8. & $\begin{array}{l}\text { Aciclovir-Farmak, } \\
\text { JSC "Farmak", Ukraine }\end{array}$ & $\begin{array}{l}\text { tablets, } \\
200 \mathrm{mg}, \\
\text { N. } 20\end{array}$ & $\begin{array}{l}\mathrm{UA} / 1325 / 02 / 01 \\
\text { Unlimited from 30.01.2019 }\end{array}$ \\
\hline 9. & $\begin{array}{l}\text { Aciclovir-Astrafarm, } \\
\text { LLC “ASTRAFARM”, } \\
\text { Ukraine }\end{array}$ & $\begin{array}{l}\text { tablets, } \\
200 \mathrm{mg}, \\
\text { N. } 10 \text {, N. } 20\end{array}$ & $\begin{array}{l}\text { UA/7833/01/01 } \\
\text { Unlimited from 11.10.2017 }\end{array}$ \\
\hline 10. & $\begin{array}{l}\text { Aciclovir, } \\
\text { Lekhim-Kharkiv Private Joint-Stock Company, } \\
\text { Ukraine }\end{array}$ & $\begin{array}{l}\text { tablets, } \\
200 \mathrm{mg}, \\
\text { N. } 10 \text {, N. } 20\end{array}$ & $\begin{array}{l}\text { UA/6895/01/01 } \\
\text { Unlimited from 28.04.2017 }\end{array}$ \\
\hline
\end{tabular}

\subsection{Pharmacoeconomic Research: ABC/VEN Analysis}

Pharmacoeconomic studies using ABC/VEN analysis made it possible to allocate drugs by the cost of pharmacotherapy and evaluate the effectiveness of drug use in hospitals (Table 3, Table 4). Using ABC analysis drugs were classified in the order of expense, where group A drugs were the most expensive, group B - less expensive, group $\mathrm{C}$ - least expensive. 
Table 3. ABC analysis of pharmaceuticals by INN Aciclovir ATC-code J05AB01 for pharmacotherapy of patients with systemic vasculitis combined with cryoglobulinemic syndrome

\begin{tabular}{llccc}
\hline No. & Trade name & Cost per unit dose (UAH) & $\begin{array}{c}\text { Specific weight } \\
\mathbf{( \% )}\end{array}$ & ABC group \\
\hline 1. & Atsik & 10,86 & 21,01 & $\mathrm{~A}$ \\
2. & Viroleks & 10,75 & 20,79 & $\mathrm{~A}$ \\
3. & Geviran & 7,56 & 14,62 & $\mathrm{~A}$ \\
4. & Aciclovir 200 STADA & 7,40 & 14,31 & $\mathrm{~A}$ \\
5. & Zoviraks & 5,00 & 9,67 & $\mathrm{~A}$ \\
\hline & Total for group A & $\mathbf{4 1 , 5 7}$ & $\mathbf{8 0 , 4 1}$ & $\mathrm{B}$ \\
\hline 6. & Herpevir & 3,21 & 6,21 & $\mathrm{~B}$ \\
7. & Aciclovir-Darnitsa & 1,92 & 3,71 & $\mathrm{~B}$ \\
\hline 8. & Aciclovir-Farmak & 1,84 & 3,56 & $\mathrm{C}$ \\
\hline & Total for group B & $\mathbf{6 , 9 7}$ & $\mathbf{1 3 , 4 8}$ & $\mathrm{93,89}$ \\
\hline & Total for groups AB: & $\mathbf{4 8 , 5 4}$ & 3,50 & \\
\hline 9. & Aciclovir-Astrafarm & 1,81 & 2,61 & $\mathbf{6 , 1 1}$ \\
10. & Aciclovir & 1,35 & $\mathbf{1 0 0 , 0 0}$ & \\
\hline & Total for group C: & $\mathbf{3 , 1 6}$ & $\mathbf{5 1 , 7}$ & \\
\hline
\end{tabular}

Table 4. VEN analysis of pharmaceuticals by INN Aciclovir ATC-code J05AB01 for pharmacotherapy of patients with systemic vasculitis combined with cryoglobulinemic syndrome

\begin{tabular}{clc}
\hline No. & Trade name & VEN group \\
\hline 1. & Atsik & $\mathrm{V}$ \\
2. & Viroleks & $\mathrm{V}$ \\
3. & Geviran & $\mathrm{V}$ \\
4. & Aciclovir 200 STADA & $\mathrm{V}$ \\
5. & Zoviraks & $\mathrm{V}$ \\
6. & Herpevir & $\mathrm{V}$ \\
7. & Aciclovir-Darnitsa & $\mathrm{V}$ \\
8. & Aciclovir-Farmak & $\mathrm{V}$ \\
9. & Aciclovir-Astrafarm & $\mathrm{V}$ \\
10. & Aciclovir & $\mathrm{V}$ \\
\hline
\end{tabular}

\section{Discussion}

In this study, the results of clinical and pharmacological analysis (Table 1) showed that the largest share of drugs for basic therapy of vasculitis (22.22\%) have following diagnostic codes of the ATC classification: A - "Drugs that affect the digestive system and metabolism" and N - "Drugs that affect the nervous system".

When studying the features of cryoglobulinemic syndrome, it was found that according to documentary data from medical cards, systemic vasculitis associated with cryoglobulinemic syndrome were listed in $31.1 \%$ (118) of medical cards.

According to marketing analysis (Table 2) for pharmacotherapy of systemic vasculitis combined with cryoglobulinemic syndrome use tablets (100\% of doctors' prescriptions). All tested drugs have an unlimited validity of registration certificates. Countries ranking of manufacturers of studied drugs follow: Ukraine $-50 \%$; 
Germany $-20 \%$; Slovenia, Poland, Spain $-10 \%$ each.

According to the results of the $\mathrm{ABC}$ analysis (Table 3), group A includes five pharmaceuticals (Atsik, Viroleks, Geviran, Aciclovir 200 STADA, Zoviraks). The unit cost is $41.57 \mathrm{UAH}$, which is $80.41 \%$ of the total cost of treatment of the patient.

Group B includes three pharmaceuticals (Herpevir, Aciclovir-Darnitsa, Aciclovir-Farmak). The total unit cost is 6.97 UAH (13.48\%).

Group C includes two pharmaceuticals (Aciclovir-Astrafarm, Aciclovir) costing 3.16 UAH per unit dose (6.11\%).

According to the results of VEN analysis (Table 4), it was proved that all ten drugs (Atsik, Viroleks, Geviran, Aciclovir 200 STADA, Zoviraks, Herpevir, Aciclovir-Darnitsa, Aciclovir-Farmak, Aciclovir-Astrafarm, Aciclovir) belong to category $\mathrm{V}$.

In categories $\mathrm{E}$ (Essential) and $\mathrm{N}$ (Non-essential) the studied drugs were not prescribed by doctors.

The distribution according to the results of VEN analysis of investigational drugs according to INN Aciclovir ATC-code J05AB01 for pharmacotherapy of patients with systemic vasculitis combined with cryoglobulinemic syndrome is shown on Figure 1.

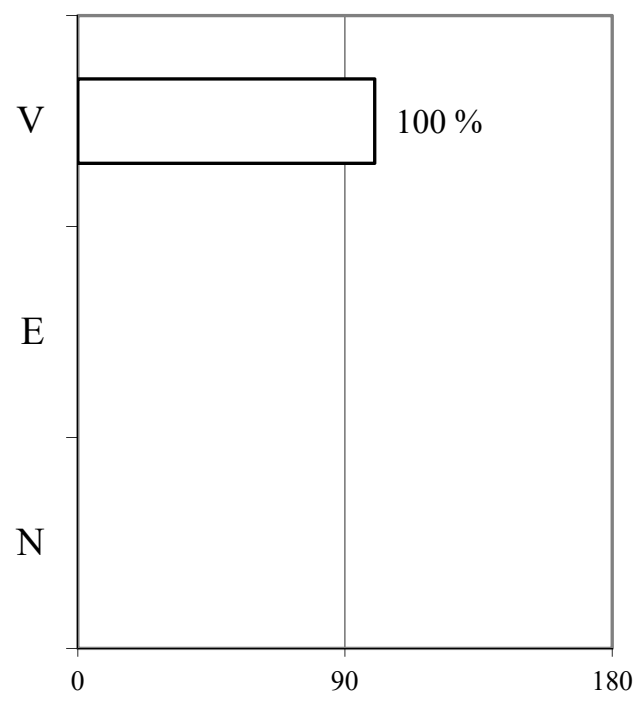

Vital: Atsik, Viroleks, Geviran, Aciclovir 200 STADA, Zoviraks, Herpevir, Aciclovir-Darnitsa, Aciclovir-Farmak, Aciclovir-Astrafarm, Aciclovir

Essential: -

Non-essential: -

Figure 1. Distribution according to the results of VEN-analysis of investigative pharmaceuticals according to INN Aciclovir ATC-code J05AB01 for pharmacotherapy of patients with systemic vasculitis combined with cryoglobulinemic syndrome

Based on the $\mathrm{ABC} / \mathrm{VEN}$ analysis, a matrix of the consolidated $\mathrm{ABC} / \mathrm{VEN}$ analysis was developed (Table 5).

Table 5. Matrix of consolidated ABC-VEN-analysis of drugs according to INN Aciclovir ATC-code J05AB01 for pharmacotherapy of patients with systemic vasculitis combined with cryoglobulinemic syndrome

\begin{tabular}{|c|c|c|c|c|c|c|c|c|c|}
\hline \multirow{3}{*}{$\begin{array}{l}\text { Drugs } \\
\text { category }\end{array}$} & \multirow{3}{*}{$\begin{array}{c}\text { Quantity of } \\
\text { drugs }\end{array}$} & \multirow{2}{*}{\multicolumn{2}{|c|}{$\begin{array}{c}\mathrm{V} \\
\begin{array}{c}\text { Drug } \\
\text { prescription }\end{array}\end{array}$}} & \multirow{3}{*}{$\begin{array}{c}\text { Quantity of } \\
\text { drugs }\end{array}$} & E & & \multirow{3}{*}{$\begin{array}{c}\text { Quantity of } \\
\text { drugs }\end{array}$} & \multirow{2}{*}{\multicolumn{2}{|c|}{$\begin{array}{c}\mathbf{N} \\
\begin{array}{c}\text { Drug } \\
\text { prescription }\end{array}\end{array}$}} \\
\hline & & & & & \multicolumn{2}{|c|}{$\begin{array}{c}\text { Drug } \\
\text { prescription }\end{array}$} & & & \\
\hline & & UAH & $\%$ & & UAH & $\%$ & & UAH & $\%$ \\
\hline $\bar{A}$ & 5 & 41,57 & 80,41 & - & - & - & - & - & - \\
\hline B & 3 & 6,97 & 13,48 & - & - & - & - & - & - \\
\hline $\mathrm{C}$ & 2 & 3,16 & 6,11 & - & - & - & - & - & - \\
\hline Total: & 10 & 51,7 & 100,00 & - & - & - & - & - & - \\
\hline
\end{tabular}


All studied drugs in the pharmacotherapy of patients with systemic vasculitis combined with cryoglobulinemic syndrome were included to the $\mathrm{V}$ (vital) category.

By categories $\mathrm{E}$ and $\mathrm{N}$ they were no doctor's appointments and costs of pharmacotherapy.

The share of distribution of drugs INN Aciclovir ATC-code J05AB01 by doctor's appointments and therapy costs by categories is calculated:

$\mathrm{A} / \mathrm{V}(80.41 \%)$ is the largest share of the total rate of doctors' appointments and the cost of maintenance therapy. The pattern of distribution in this category was the same among all studied drugs. For example, five drugs belong to category A (Atsik, Viroleks, Geviran, Aciclovir 200 STADA, Zoviraks) among studied drugs.

B/V (13.48\%): three drugs belong to category B (Herpevir, Aciclovir-Darnitsa, Aciclovir-Farmak) among studied drugs.

C/V (6.11\%): two drugs belong to category C (Aciclovir-Astrafarm, Aciclovir) among studied drugs.

\section{Conclusion}

The relevance and necessity of the chosen research topic as a result of a review of the scientific literature on the epidemiology and pharmacotherapy of patients with systemic vasculitis associated with cryoglobulinemic syndrome was substantiated in the study.

Clinical and pharmacological analysis of basic therapy of systemic vasculitis was performed. The largest share of drugs of basic therapy included diagnostic ATC codes "A" - The means influencing digestive system and a metabolism and code " $\mathrm{N}$ " - The means influencing a nervous system. Marketing research of drugs according to INN Aciclovir ATC code J05AB01 for pharmacotherapy of patients with systemic vasculitis combined with cryoglobulinemic syndrome by range, country of origin, dosage forms, and registration certificates were conducted.

According to the results of $\mathrm{ABC}$ analysis, drugs for pharmacotherapy of patients with systemic vasculitis combined with cryoglobulinemic syndrome were distributed in descending order of value. It is noted that the cheapest, with a high level of affordability (category C) are only two drugs (Aciclovir-Astrafarm, Aciclovir) that occupy $6.11 \%$ of appointments and expenses. There are five drugs that belong to group $\mathrm{A}$ - the most expensive, with a low level of affordability which occupy $80.41 \%$ of the total number of appointments and costs for maintenance therapy.

After completing of the VEN analysis, it was estimated that category V (vital) drugs accounted for the largest number of prescriptions and the cost of therapy $(100 \%)$. It was also noted that in the $\mathrm{A} / \mathrm{E}$ categories drugs coincide and are in a niche with an affordable share $(17.04 \%)$.

In terms of priority for the pharmacotherapy of patients with systemic vasculitis associated with cryoglobulinemic syndrome, a matrix of consolidated ABC/VEN - analysis of drugs according to INN Aciclovir ATC-code J05AB01 was developed. The purpose of the study was achieved.

The results of the study provide an opportunity to make administrative and managerial decisions in determining the pharmacotherapy of patients with systemic vasculitis combined with cryoglobulinemic syndrome to improve the use of drugs in hospitals. Further researches in area needed, including analysis of the most important side effects of appointed drugs in comparing them with their costs.

\section{Competing Interests Statement}

The authors declare that there are no competing or potential conflicts of interest.

\section{References}

Beketova, T. V., Blank, L. M., \& Lila, A. M. (2020). Covid-19 in a patient with anca-associated systemic vasculitis, receiving anti-b cell therapy (rituximab). Rheumatology Science and Practice. https://doi.org/10.14412/1995-4484-2019-597-603

Fellner, C. (2016). Biologics will pump up the vasculitis market. Pharmacy and Therapeutics, 41(4), 258. Retrieved from https://pubmed.ncbi.nlm.nih.gov/27069346/

Hayduchok, I. G., Shapovalova, V. O., Shapovalov, V. V. (Jr.), \& Shapovalov, V. V. (Jr.) (2020). Control regime of antibacterial drugs for pharmacotherapy of coronavirus disease (COVID-19) among patients with dual disorders. An information letter about innovations Ukrmedpatentinform of the Ministry of Health of Ukraine (N. 230-2020, P. 6). Ukrmedpatentinform of the Ministry of Health of Ukraine. 
Hayduchok, I. G., Shapovalova, V. O., Shapovalov, V. V. (Jr.), \& Shapovalov, V. V. (2020). Control regime of drugs for pharmacotherapy of coronavirus disease (COVID-19) in patients with systemic diseases. An information letter about innovations Ukrmedpatentinform of the Ministry of Health of Ukraine (N. 225-2020, P. 6). Ukrmedpatentinform of the Ministry of Health of Ukraine.

Hayduchok, I. G., Shapovalova, V. O., Shapovalov, V. V. (Jr.), \& Shapovalov, V. V. (2021). Control regime of drugs for pharmacotherapy vasculitis of Shenlein-Genoch: An information letter about innovations Ukrmedpatentinform of the Ministry of Health of Ukraine (N. 64-2021, p. 7). Ukrmedpatentinform of the Ministry of Health of Ukraine.

International Guideline 00449. (2017). Vasculitis. Tom Pettersson. Original text editor: Anna Kattainen (last updated on: 2017-08-01).

International Guideline 00653. (2016). Purple Shenlein-Genoch. Pekka Lahdenne (last updated on: 2017-01-16).

Kuzmina, A. P. (2015). Systemic vasculitis: a diagnostic search in real clinical practice. Health of Ukraine, 3(40), 42-44.

Mamarde, A. (2016). ABC/VEN Analysis of drug store in Tertiary care hospital for year 2013-2014. American Journal of Pharmaceutical Research, 6(8), 6439-6444.

Management Science for Health. Managing Medicines Selection. (2012). In Managing Access to Medicines and Health Technologies (16.1-16.15). Arlington, VA, USA: MSH.

Marushko, T. V. (2020). Systemic vasculitis: principles of diagnosis and treatment. Pediatrics, 1(52). Retrieved from https://health-ua.com/article/46571-sistemn-vaskulti-printcipi-dagnostiki-talkuvannya

National list of basic medicines. (2009). Resolution of the Cabinet of Ministers of Ukraine of 25.03.2009 №333. Retrieved from http://zakon.rada.gov.ua

Order of the Ministry of Health of Ukraine. (2020). On approval of the twelfth issue of the State formulary of medicines and ensuring its availability. Dated 06.05.2020 N.1075. Retrieved from https://zakon.rada.gov.ua

Shapovalov, V. V., Gudzenko, A. O., Andrieieva, V. V., \& Shapovalova, V. O. (2019). Experience of the USA concerning an organization of healthcare system for pharmaceutical provision for privileged categories of citizens. Annals of Mechnikov institute, (1), 81-87. https://doi.org/10.5281/zenodo.2639521

Shapovalov (Jr.), V. V., Gudzenko, A. A., Shapovalova, V. A., \& Shapovalov, V. V. (2020). Forensic and pharmaceutical analysis of addictive morbidity because of the use of psychoactive substances in Ukraine. Klin. inform. telemed, 15(16), 125-128. https://doi.org/10.31071/kit2020.16.02

Shapovalov (Jr.), V. V., Shapovalova, V. O., Andrieieva, V. V., \& Shapovalov, V. V. (2019). Experience of Great Britain in organization of healthcare system for pharmaceutical provision with medicines for privileged categories of citizens. Health of society, 78(1), 36-40. https://doi.org/10.22141/2306-2436.8.1.2019.172617

Shapovalov (Jr.), V., Gudzenko, A., Komar, L., Butko, A., Shapovalova, V., \& Shapovalov, V. (2017). Concerning the importance of forensic and pharmaceutical researches to improve patients accessibility to medicines. Pharmacia, 65(2), 23-29.

Shapovalov (Jr.), V., Gudzenko, A., Shapovalov, V., \& Shapovalova, V. (2018). Organizational and legal aspects of the use of pharmacoeconomic analysis of multivitamin complexes for pharmaceutical provision of military personnel. The Pharma Innovation Journal, 7(10), 166-169.

Shapovalov (Jr.), V., Gudzenko, A., Shapovalova, V., Osyntseva, A., \& Shapovalov, V. (2017). Forensic and pharmaceutical study of the presence of a causal link between the degree of alcohol abuse and qualification level of the respondents. Pharmacia, 66(3), 31-39.

Shapovalov (Jr.), V., Zbrozhek, S., Gudzenko, A., Shapovalova, V., \& Shapovalov, V. (2018). Organizational and legal analysis of the pharmaceutical provision for the most common diseases of society. International Journal of Pharmaceutical Sciences Review and Research, 51(1), 18, 118-124.

Shapovalova, V. O., Zbrozhek, S. I., Shapovalov (Jr.), V. V., \& Shapovalov, V. V. (2021). Forensic pharmacy: some risk factors in the formation of addictive health disorders. Acta Scientific Pharmaceutical Science, 4(1), 7-12. https://doi.org/10.3180/ASPS.2020.05.0651

Shapovalova, V. O., Zbrozhek, S. I., Shapovalov, V. V. (Jr.), \& Shapovalov, V. V. (2020). Coronavirus disease pandemia 2019: growth of epidemic dangers. Acta scientific pharmaceutical science, 2, 2020. https://doi.org/10.31080/ASPS.2020.04.0559 
Snow, J. (2005). United States Agency for International Development. Logistics Indicators Assessment Tool. Arlington, VA.: John Snow, Inc./ DELIVER.

Vasculitis: 5 Drugs to Control This Mysterious Blood Vessel Illness. (2017). Cleveland Clinic. Retrieved from https://health.clevelandclinic.org/4-medicines-help-you-manage-the-mysteries-of-vasculitis/

Vincent, M., \& Brown, N. (2015). Managing ANCA-associated vasculitis. The Pharmaceutical Journal. Retrieved from https://pharmaceutical-journal.com/article/ld/managing-anca-associated-vasculitis.

\section{Copyrights}

Copyright for this article is retained by the author(s), with first publication rights granted to the journal.

This is an open-access article distributed under the terms and conditions of the Creative Commons Attribution license (http://creativecommons.org/licenses/by/4.0/). 